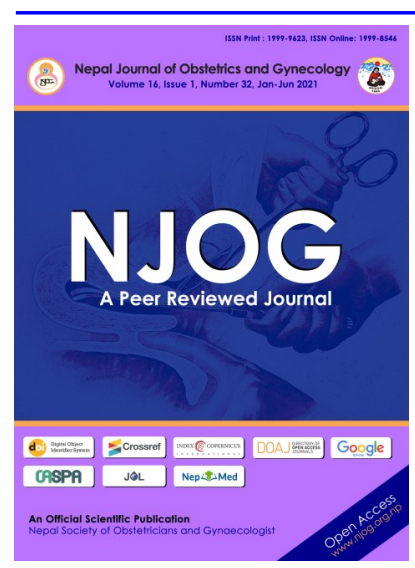

CORRESPONDENCE

Dr Reetu Sharma Baral

Department of Pathology, Nobel Medical College, Biratnagar, Nepal

Email:

reetu.baral@gmail.com; Phone:+977-9841829242

Received: May 52020

Accepted: May 20, 2021

\section{Citation:}

Baral RS, Shrestha O. Histomorphological spectrum of Leiomyoma - a one year retrospective study. Nep J Obstet Gynecol. 2021;16 (32):77-80. DOI: https:// doi.org/10.3126/ njog.v16i1.37609

\title{
Histomorphological spectrum of Leiomyoma - a one year retrospective study
}

\author{
Reetu Sharma Baral, Oshan Shrestha \\ Department of Pathology, Nobel Medical College Teaching Hospital, \\ Biratnagar, Nepal
}

\section{ABSTRACT}

Aims: To analyze the histomorphology of leiomyoma in specimens received in the Department of Pathology.

Methods: This is a retrospective descriptive study of histopathology database of histomorphologic spectrum of leiomyoma at Pathology Laboratory of Nobel Medical College Teaching Hospital, Biratnagar, Nepal from April 2020 to April 2021. Data for the leiomyoma were analyzed descriptively. Ethical approval was obtained from the Institutional review committee.

Results: A total of 1705 histopathology specimens were received in one year from April 2020 to April 2021 out of which 620 (37\%) were from the Department of Gynecology and Obstetrics for histopathological analysis of various specimens. Total of 106 specimens of hysterectomy and myomectomy were included. Maximum number of leiomyoma was seen in the body $48(45 \%)$ followed by fundus $34(32 \%)$ and one from the lateral wall of the vagina $1(0.9 \%)$. Mean age was 42 (24-70) years. Maximum size was $35 \mathrm{~cm}$ and minimum was $0.5 \mathrm{~cm}$ in diameter. Out of the rare ones one case of STUMP, Lipoleiomyoma and Mitotically active leiomyoma each were seen. Degenerative change was in 40 cases with hyaline type as the commonest one (33\%); $61 \%$ were intramural; and $12 \%$ were multiple. Presentation was lower abdominal pain and abnormal uterine bleeding in $39.6 \%$.

Conclusions: Cases of leiomyoma may present with abdominal mass, pain and bleeding but the degenerative changes and malignant transformation can't be identified without histopathological examination.

Keywords: abnormal uterine bleeding, degenerative changes, leiomyoma, myomectomy

\section{INTRODUCTION}

Leiomyoma (fibroid) are benign tumors which arise from the smooth muscle cells of the myometrium. ${ }^{1}$ These are the most common benign tumors of uterus affecting $20-40 \%$ women of reproductive age group..$^{2-4}$ The diagnosis is easily established by complete history and radiological findings. The histopathological examination analyses are the important tool to qualify and quantify the tumor according to the histopathological parameters that enable differential diagnosis of the neoplasm. The histomorphological changes subsequent to increased angiogenensis rate and proliferation of myomatous and fibroblast cells results in homoge- nous appearance consisting of large bundles of smooth muscles cells, which are crisscrossed and arranged in fascicles mimicking the normal myometrial appearance. Various types of degenerative changes like hyaline, myxoid, cystic as well as dystrophic calcifications can be discerned.

Leiomyomas are the common findings in women with AUB. The abnormal bleeding in fibroids is due to increased size of uterine cavity thereby increasing the surface area of the endometrium, hyperestrogenemia causing endometrial hyperplasia, vascular alterations of the endometrium and obstructive effect of fibroid on uterine vasculature leading to en- 
dometrial venule ectasia which causes proximal congestion in the myometrium and endometrium. Majority of the women having uterine fibroid with AUB are treated by hysterectomy. ${ }^{5-8}$

The aim of our study is to analyze various histopathological changes within the uterine leiomyoma in both hysterectomy and myomectomy specimens. And also, to analyze the site, size, degenerative changes, number and clinical manifestations associated with it.

\section{METHODS}

This is a retrospective descriptive study of pathology lab database analysis of histopathology specimens for Leiomyoma. The data were searched by primary search key "leiomyoma" and secondary search keys like "hyaline", "myoma", "abnormal uterine bleeding" and "fibroid". The data from April 2020 to April 2021 were searched for the study. These data were entered and exported from Microsoft Excel to SPSS 20 Window to analyze. Results are presented in charts and tables by descriptive parameters.

\section{RESULTS}

Out of 1705 histopathology specimens received from April 2020 to April 2021, 620 (37\%) specimens were from Department of Gynecology and Obstetrics. In this study a total of 106 specimens were included which consisted of hysterectomies, both abdominal and vaginal as well as laparoscopic myomectomy specimens. Hysterectomy specimens were $91(85.8 \%)$ and myomectomy specimen were $15(14.2 \%)$. In the present study, patients with leiomyomas were aged between 24 and 70 years with both mean and median age of 43 years. Majority 60 $(56.6 \%)$ were in the age group of $40-49$ years. [Figure-1]

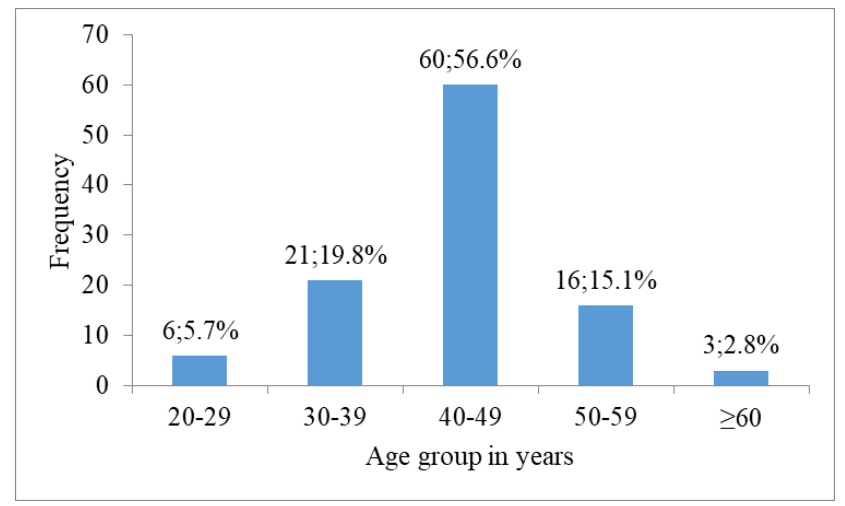

Figure-1: Age group distribution $(\mathrm{N}=106)$
Abnormal uterine bleeding with lower abdominal pain was seen in $42(39.6 \%)$, other clinical manifestaions like pain abdomen $36(34 \%)$, mass in the pelvic area $8(8.4 \%)$ and uterovaginal prolapse 3 $(2.8 \%)$ were also seen in the rest. Most common site for leiomyoma was the body $48(45 \%)$ followed by fundus 34 (32\%) of the uterus. Leiomyo$\mathrm{ma}$ in the broad ligament was seen in $4(3.8 \%)$ where the patients were all in their thirties. The least number was seen arising from the lateral wall of the vagina $1(0.9 \%)$. Maximum size was $35 \mathrm{~cm}$ and minimum was $0.5 \mathrm{~cm}$ in diameter.

Most of the uteri leiomyoma were single accounting for $79(74.5 \%)$ cases and in the remaining 27 $(25.5 \%)$ cases the number varied from 2 to 10 . In the present study, with respect to location, majority $(67 ; 63.2 \%)$ were intramural leiomyoma followed by submucosal $(14 ; 13.2 \%)$ and subserosal $(7$; $6.6 \%)$; and multiple location was seen in 13 $(12.3 \%)$ cases.

Out of 106 specimens 54 (51\%) were fibroid without any other microscopic changes. Adenomyosis was seen in $9(8.4 \%)$ cases. The rare ones were STUMP (smooth muscle tumor of unknown malignant potential), Lipoleiomyoma and Mitotically active leiomyoma each. [Figure-2]

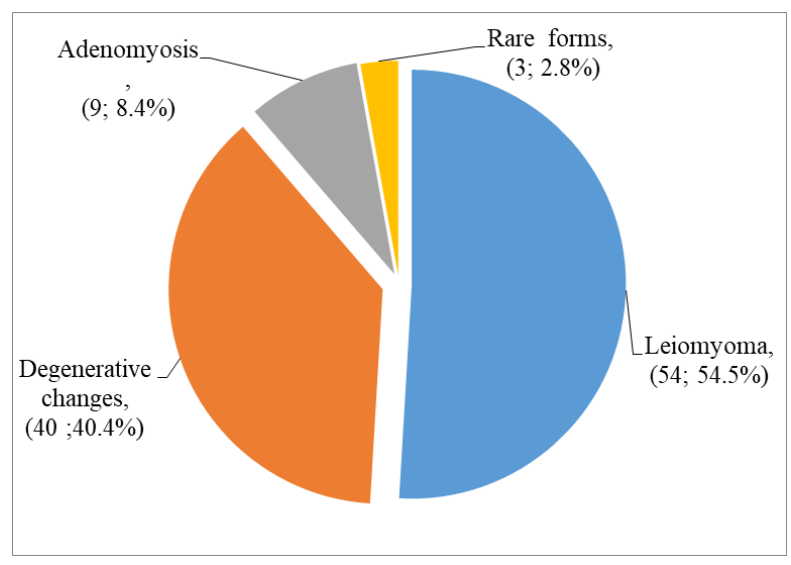

Figure-2: Histopathology of specimens $(\mathrm{N}=106)$

Grossly, 10 (9.4\%) showed degenerative changes. Microscopically, various histopathological changes occurring within leiomyomas were present in 40 $(37.7 \%)$ of cases. Hyaline degeneration was the most common secondary degenerative changes. [Figure-3]

\section{DISCUSSION}

Leiomyomas are benign uterine neoplasm which account for one of the most common causes of 


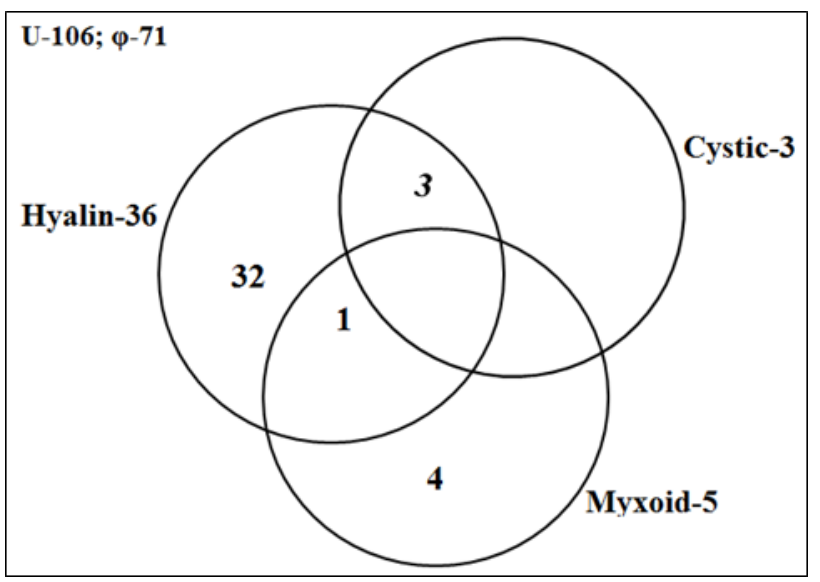

Figure-3: Venn diagram showing degenerative changes $(\mathrm{N}=40)$

morbidity in the premenopausal age group. It is one of the most common indications for hysterectomy followed by Adenomyosis. ${ }^{8}$ In this study the mean age group is 42 years (24 to 70 ). This is similar to studies done by various researchers of the region. ${ }^{9-11}$ Leiomyoma comprised of $17 \%$ of all gynecology samples received in one year which is a little less than other studies done. ${ }^{9-12}$

Literatures have shown that patients with uterine leiomyoma are asymptomatic, but if symptoms do appear it is usually manifested as lower abdominal pain and abnormal uterine bleeding (AUB). In the present study also it was seen in $42(39.6 \%)$ cases followed by pain abdomen $(36 ; 34 \%)$. The pain abdomen maybe due to the degenerative changes that occur within the leiomyoma. ${ }^{12-14}$

In the present study, number of leiomyoma in the uterus varied from $1-10$, of which $79(74.5 \%)$ were single which is in accordance with the study done by K Geethmala et al, ${ }^{12} \mathrm{~S}$ Bhatta ${ }^{15}$ as well as Rosario. ${ }^{16}$ Most of the leiomyomas were intramural in location $67(63.2 \%)$ which is similar to studies done by different researchers. ${ }^{12-16}$

In the current study, secondary degenerative changes were noted grossly in $10(9.4 \%)$ cases. Microscopically histopathological degenerative changes were seen in $40(37.7 \%)$. The degenerative changes in leiomyomas occur due to inadequate blood supply which may result in hyalinization, followed by cystic, myxoid, hydropic, hemorrhagic and calcification. The type of secondary changes depends on the rapidity and degree of vascular insufficiency. ${ }^{12,17,18}$ These secondary changes usually occur in old matured lesions and hence careful histopathological sampling should be carried out.
Lipoleiomyoma is a rarer variant of uterine leiomyoma showing histological features of varying amount of mature adipocytes amidst smooth muscle cells. In our study we had one case which is similar to studies done by Abraham and Saldanha where the frequency was $4(0.7 \%) .{ }^{19}$

STUMP is defined by WHO as smooth muscle tumor that cannot be histologically diagnosed as unequivocally benign or malignant. Microscopy reveals minimal atypical smooth muscle neoplasm with low mitotic index $<10 / 10$ high power field but uncertainty about tumor necrosis. ${ }^{20}$ Ip et al studied 16 cases of STUMP and concluded saying that these are usually benign but should be considered tumors of low malignant potential since they recur after years of hysterectomy. ${ }^{20}$ In the present study we had one case only over the one year period.

\section{CONCLUSIONS}

Leiomyomas are benign tumors of the smooth muscle cells frequently seen in perimenopausal women. The present study highlights the different histomorphology of the lesion which explains the different clinical manifestations. Therefore, a complete histopathological examination should be made mandatory for confirm diagnosis, further management and complete treatment of the concerned patients.

\section{REFERENCES}

1. Crum CP. Body of uterus and endometrium. In: Kumar V, Abbas AK, Fausto N, Eds. Robbins and Cotran Pathologic Basis of Disease. 7th ed. Philadelphia: Saunders, 2004:1089-90.

2. Wallach EE, Vlahos NF. Uterine myomas: an overview of development, clinical features, and management. Obstet Gynecol. 2004;104(2):393 -406 .

3. Payson M, Leppert P, Segars J. Epidemiology of myomas. Obstet Gynecol Clinics North Am. 2006;33(1):1-11.

4. da Silva AP, Mello Lde A, Dos Santos ER, Paz ST, Cavalcanti CL, de Melo-Junior MR. Histopathological and Digital Morphometrical Evaluation of Uterine Leiomyoma in Brazilian Women. Obstet Gynecol Int. 2016;2016:2968410. doi: 10.1155/2016/2968410 Epub 2016 May 15. PMID: 27293441; PMCID: PMC4884588. 
5. Bhosle A, Fonseca M. Evaluation and histopathological correlation of abnormal uterine bleeding in perimenopausal women. Bombay Hosp J. 2010;52:69-72.

6. Rashida Hafiz, Muhammad Ali, Mansoor Ahmad. Fibroid as a causative factor in menorrhagia and its management. Pakistan J Med Res. 2003;42:90-6

7. Mukherjee SN. Role of hysterectomy and its alternatives in benign uterine diseases. J Indian Medical Assoc. 2008;106:232-6.

8. Rani SV, Thomas S. Leiomyoma, a major cause of abnormal uterine bleeding. J Evol Med Dent Sci. 2013;2:2626-30.

9. Rizvi G, Pandey H, Pant H, Chufal SS, Pant P. Histopathological correlation of adenomyosis and leiomyoma in hysterectomy specimens as the cause of abnormal uterine bleeding in women in different age groups in the Kumaon region: A retroprospective study. J Midlife Health. 2013;4(1):27-30. doi: 10.4103/09767800.109631 PMID: 23833530; PMCID: PMC3702061.

10. Vaidya S, Vaidya SA. Patterns of lesions in hysterectomy specimens in a tertiary care hospital. J Nepal Med Assoc. 2015;53(197):18-23.

11. Baral R, Sherpa P, Gautam D. Histopathological analysis of hysterectomy specimens: one year study. J Path Nep. 2017;7(1):1084-6. URL: https://www.nepjol.info/index.php/JPN/article/ view/16942

12.Geethamala K, Murthy VS, Vani BR, Rao S. Uterine Leiomyomas: An enigma. J Midlife Health. 2016;7(1):22-7. doi: 10.4103/09767800.179170 PMID: 27134477; PMCID: PMC4832891.
13. Begum S, Khan S. Audit of leiomyoma uterus at Khyber teaching hospital Peshawar. J Ayub Med Coll Abbottabad. 2004;16(2):46-9. PMID: 15455617.

14.Jaiswal CJ. Vaginal management of uterocervical myomas. J Obstet Gynecol India. 1996;46:260-3.

15.Bhatta S, Bhandari S, Osti B. Histopathological study of Uterine Leiomyoma in Hysterectomy Specimens. Annal Clin Chem Lab Med. 2018;3 (2):16-0. Available from: https:// www.nepjol.info/index.php/ACCLM/article/ view/20739

16. Rosario YP. Uterine leiomyomas. J Obstet Gynecol India. 1968;18:101-7.

17.Persaud V, Arjoon PD. Uterine leiomyoma. Incidence of degenerative change and a correlation of associated symptoms. Obstet Gynecol. 1970;35(3):432-6. PMID: 4190425.

18.Prayson RA, Hart WR. Pathologic considerations of uterine smooth muscle tumors. Obstet Gynecol Clin North Am. 1995;22(4):637-57. PMID: 8786875.

19.Abraham J, Saldanha P. Morphological variants and secondary changes in uterine leiomyomas Is it important to recognise them? Int J Biomed Res. 2013;4:639-45.

20.Ip PP, Cheung AN, Clement PB. Uterine smooth muscle tumors of uncertain malignant potential (STUMP): a clinicopathologic analysis of 16 cases. Am J Surg Pathol. 2009;33 (7):992-1005. doi: 10.1097/ PAS.0b013e3181a02d1c PMID: 19417585. 